\title{
Retraction of DNA Cell Biol: 31:1064-1069, 2012, DOI: 10.1089/dna.2011.1552
}

DA AND CELL BIOLOGY (DNA\&CB) is officially retracting the paper by Ma L, Zhang H, Han C, Tong D, Zhang M, Artery Disease," 31:1064-1069, 2012, DOI: 10.1089/dna.2011.1552, due to a striking overlap with two other published papers:

- Chen H, Tong J, Zou T, Shi H, Liu J, Du X, Yang J, Ma C Fibroblast growth factor receptor 4 polymorphisms are associated with coronary artery disease. Genet Test Mol Biomarkers, 16:952-956, 2012, DOI: 10.1089/ gmtb.2012.0033.

- Zhu Q, Liu T. Fibroblast growth factor receptor 4 polymorphisms and coronary artery disease: a case control study. Mol Bio Report 39:8679-8685, 2012, DOI: 10.1007/s11033-012-1723-1728.

The abstracts and introductions in each published paper are nearly identical. The data sets are modestly different, but indicate the same findings.

The paper was submitted to and reviewed in $D N A \& C B$ in 2011, prior to the Journal's current policy whereby only reviewers with institutional email addresses are utilized for peer review.

For these reasons, DNA and Cell Biology is retracting Ma, et al., 31:1064-1069, 2012, DOI: 10.1089/dna.2011.1552. 